\title{
Gilles Vidal, Les nouvelles théologies protestantes dans le Pacifique Sud. Étude critique d'un discours religieux et culturel contemporain
}

Paris, Éditions Karthala, coll. « Hommes et sociétés », 2016, 463 p., préface de Jean-François Zorn

Gwendoline Malogne-Fer

\section{OpenEdition}

\section{Journals}

Édition électronique

URL : http://journals.openedition.org/assr/28360

DOI : $10.4000 /$ assr.28360

ISSN : $1777-5825$

Éditeur

Éditions de l'EHESS

Édition imprimée

Date de publication : 31 décembre 2016

Pagination : 399

ISSN : 0335-5985

Référence électronique

Gwendoline Malogne-Fer, « Gilles Vidal, Les nouvelles théologies protestantes dans le Pacifique Sud. Étude critique d'un discours religieux et culturel contemporain », Archives de sciences sociales des religions [En ligne], 176 | octobre-décembre 2016, mis en ligne le 20 juillet 2017, consulté le 24 septembre 2020. URL : http://journals.openedition.org/assr/28360 ; DOI : https://doi.org/10.4000/ assr.28360

Ce document a été généré automatiquement le 24 septembre 2020

(C) Archives de sciences sociales des religions 


\section{Gilles Vidal, Les nouvelles} théologies protestantes dans le Pacifique Sud. Étude critique d'un discours religieux et culturel contemporain

Paris, Éditions Karthala, coll. « Hommes et sociétés », 2016, 463 p., préface de Jean-François Zorn

\section{Gwendoline Malogne-Fer}

\section{RÉFÉRENCE}

Gilles Vidal, Les nouvelles théologies protestantes dans le Pacifique Sud. Étude critique d'un discours religieux et culturel contemporain, Paris, Éditions Karthala, coll. « Hommes et sociétés », 2016, 463 p., préface de Jean-François Zorn

1 Cet ouvrage, à la croisée de la théologie, de l'histoire et l'anthropologie des religions, est issu d'une thèse de doctorat soutenue en 2011 en histoire contemporaine et en théologie protestante intitulée Les théologies contextuelles dans le Pacifique sud au $\mathrm{XX}^{e}$ siècle. Analyse des conditions de production d'un discours religieux en situation. Gilles Vidal y analyse à partir d'un riche corpus (mémoire et thèses d'étudiants en théologie, articles et rapports d'églises) les théologies protestantes contextuelles en Océanie. Ces dernières sont définies comme des discours religieux qui pour être pertinents doivent pouvoir s'émanciper des théologies classiques héritées de la période missionnaire (associant trop étroitement christianisme et culture occidentale) en s'inscrivant pleinement dans des contextes particuliers, c'est-à-dire dans des cultures océaniennes qui sont elles-mêmes l'objet de réinterprétations. Ces théologies se sont développées à partir des années 1960-1970 dans un tournant marqué par l'indépendance 
organisationnelle des Églises vis-à-vis des sociétés missionnaires, l'indépendance politique de nombreux pays d'Océanie (Samoa, Fidji, Vanuatu), et par la structuration d'un mouvement œcuménique au niveau régional, la Pacific Conference of Churches (PCC), associé à l'établissement d'un lieu de formation théologique, le Pacific Theological College (PTC).

2 Dans la première partie de l'ouvrage, «De l'émergence à la reconnaissance. Trois figures de proue de la théologie océanienne des années 1970 aux années 2000 », l'auteur étudie plus spécifiquement la production de trois grands théologiens protestants: le Tongien Sione "Amanaki Havea auteur de « la théologie de la noix de coco » (chap. 1), le Fidjien Sevati Tuwere et «la théologie du lieu » (chap. 2) et le Samoan Ama 'Amalele Tafaeno et «l'éco-théologie» (chap.3). Le lecteur est d'emblée plongé dans l'interprétation de symboles, de pratiques ou mythes océaniens au regard des différentes significations bibliques qu'ils peuvent revêtir.

3 La seconde partie adopte une approche synchronique et propose un tableau d'ensemble de la théologie protestante océanienne contemporaine à partir de quatre grands thèmes qui renvoient chacun à des thématiques classiques de la théologie : le discours sur Dieu est abordé à partir d'une réflexion sur l'importance du fenua (terre) en Océanie comme lieu de présence implicite ou de révélation explicite du Dieu biblique (chap. 4); le discours christologique est analysé à travers différentes figures (le chef, le serviteur, le poteau central) et, en Mélanésie, l'importance symbolique, religieuse et culturelle, du sacrifice du porc dans les cérémonies traditionnelles est mise en parallèle avec la figure $\mathrm{du}$ Christ (chap. 5). Les similitudes entre symboles culturels et bibliques sont parfois telles que l'auteur en vient à se demander s'il ne s'agit pas d'une relecture chrétienne de symboles culturels préchrétiens: «le plus frappant dans ces observations d'ordre ethnographique est la récurrence de termes également communs à la théologie chrétienne, comme s'il s'agissait d'une relecture de la religion traditionnelle à partir d'un prisme chrétien » (p. 200).

4 Les théologies qui sont davantage ancrées dans une perspective anthropologique font l'objet des deux chapitres suivants: «la théologie de la célébration» réaffirme, à travers différentes cérémonies (comme celle du kava), l'unité et la réconciliation communautaire; l'auteur regroupe ensuite, sous le terme flottant de " théologies de l'identité ", des approches sensiblement divergentes les unes des autres (chap. 6). Enfin la troisième partie de l'ouvrage (chap. 8 et 9), plus théorique, repère à partir des exemples océaniens précédemment étudiés «les caractéristiques générales de la contextualisation de la théologie en tant que processus » (p. 20).

5 L'intérêt majeur de cet ouvrage est de rendre accessible au public francophone un ensemble diversifié de productions théologiques et de les faire dialoguer entre elles. L'auteur met particulièrement bien en évidence la cohérence des textes choisis et la pertinence d'une approche comparative : ces théologies contextuelles, aussi singulières soient-elles, développent des thématiques et des approches sensiblement comparables et intelligibles pour autrui et ce même si - l'auteur le rappelle - une des difficultés de ces théologies contextuelles vient du fait qu'un même symbole peut selon les îles revêtir des significations différentes voire profondément divergentes.

6 L'approche compréhensive des écrits des théologiens anglophones contraste avec l'approche plus critique des théologiens francophones, ce qui soulève un certain nombre d'interrogations. Tout se passe comme si les relations de dépendance maintenues entre la France métropolitaine et les (anciennes) colonies françaises du 
Pacifique induisait de facto un regard plus exigeant vis-à-vis des théologiens de Nouvelle-Calédonie et surtout de Polynésie française. Les critiques adressées à Turo Raapoto - notamment celles de développer une théologie nationaliste et de prôner une «identité fermée » - illustrent cette différence de traitement. Sans nier la dimension idéologique et politique de l'approche de Turo Raapoto, la critique en termes d'enfermement identitaire aurait pu être resituée, de façon plus nuancée, dans l'histoire du renouveau culturel polynésien et dans le contexte politique spécifique de la Polynésie française marqué en particulier par les essais nucléaires.

Bien que l'auteur précise en introduction qu'«il ne s'agit pas tenir ici des propos et de fournir des jugements normatifs sur la théologie océanienne» (p. 16), l'ouvrage comporte plusieurs parties consacrées à l'évaluation de ces productions théologiques. L'évaluation théologique est intéressante en ce sens qu'elle fait découvrir les règles propres à cette discipline; elle souligne également toute la difficulté de l'exercice puisque les théologiens océaniens doivent se démarquer des théologies classiques occidentales tout en se conformant à un ensemble de règles considérées comme allant de soi : "le discours théologique, quel qu'il soit, obéit à la fois à certaines règles internes en se confrontant avec des loci particuliers hérités de sa longue histoire, comme la nature de Dieu, son mode de révélation, la question de la foi humaine, le rapport de celle-ci aux textes sacrés et aux rites instaurés par la tradition, etc.» (p. 125). En revanche l'évaluation critique de certaines théologies contextuelles basée sur des critères sociologiques est plus difficilement recevable. Les théologies féministes semblent ainsi d'emblée disqualifiées au motif d'une part que ces théologiennes s'inspireraient trop des approches féministes américaines et d'autre part parce qu'elles occuperaient des positions sociales qui les éloigneraient de la base et des réalités sociales au cœur des théologies contextuelles. Mais cet argument - qui pourrait d'ailleurs être appliqué aux hommes théologiens - apparait d'une utilisation malaisée puisque le corpus choisi - les productions écrites en langue anglaise ou française suppose de facto de s'intéresser exclusivement à des personnes diplômées, qui, du fait de leurs parcours universitaires, font partie des intellectuels océaniens.

8 Les théologiens dont les productions ont été étudiées en détail dans la première partie, notamment Havea et Tuwere, ont eu des responsabilités importantes au niveau ecclésial, œcuménique (PCC) et académique (PTC) ce qui les inscrit dans des réseaux internationaux et des circulations transnationales d'échanges intellectuels entre les îles d'Océanie, la Nouvelle-Zélande, l'Australie, les États-Unis ou l'Allemagne. En d'autres termes, la mondialisation religieuse dans laquelle s'inscrivent ces théologiens ne permet pas de distinguer des productions théologiques "endogènes" de celles qui seraient « exogènes » et de ce fait disqualifiées. En anthropologie de l'Océanie, les vifs débats autour de "l'invention de la tradition " ont été l'occasion de rappeler la non pertinence des catégorisations en «vraies» et «fausses» traditions. Ces catégorisations reposent sur une vision essentialiste des cultures océaniennes alors que les anthropologues devraient s'attacher à comprendre comment ces traditions et cultures sont vécues quotidiennement de manière cohérente et continue par les individus. Ces catégorisations privilégient également une vision anhistorique des cultures océaniennes conduisant à une conception négative des changements sociaux et historiques incluant l'évangélisation des îles du Pacifique au XIXe siècle. L'auteur souligne d'ailleurs en conclusion de l'ouvrage tout l'intérêt qu'il y aurait à poursuivre ces recherches sur les théologies contextuelles en Océanie en s'interrogeant, dans une perspective anthropologique, sur le christianisme et le changement culturel, en termes 
de discontinuité/continuité. Ce type de recherches permettrait sans doute de nuancer, par endroits, la rupture que ces théologies contextuelles sont censées constituer vis-àvis des théologies et pratiques missionnaires. Il est par exemple difficile, concernant la Polynésie française, de ne pas faire le lien entre «la théologie de la terre » et les pratiques et enseignements missionnaires valorisant la culture agricole et privilégiant le ministère de pasteur-agriculteur jusque dans les années 1970.

Ces remarques et réflexions n'enlèvent évidemment rien au fait que ce livre constitue une contribution importante, accessible et documentée, à l'analyse des christianismes d'Océanie en mobilisant une approche originale, à la croisée de la théologie et des sciences humaines. Cette étude des relations entre protestantisme et cultures locales permet de mieux saisir la richesse et la diversité de ces écrits théologiques qui participent à l'élaboration de traditions chrétiennes océaniennes au sein desquelles l'affirmation autochtone et la revendication d'une identité chrétienne sont indissociablement liées. Les théologies contextuelles sont définies dans l'ouvrage comme des théologies ancrées dans l'expérience, des théologies indissociables de la vie communautaire et qui accordent une grande importance aux destinataires. Il reste donc à analyser la diffusion de ces théologies contextuelles en Océanie, c'est-à-dire la manière dont elles sont comprises, acceptées ou critiquées, associées ou non à des enseignements théologiques "classiques", et mises en pratique dans de nouvelles liturgies. 